\title{
GAMBARAN PENERAPAN PENDOKUMENTASIAN ASUHAN KEBIDANAN DIBPS WILAYAH KERJA KECAMATAN SINGAPARNA TAHUN 2015
}

Oleh :

Chanty Yunie HR, SST, M.Kes

\section{A. Abstrak}

Berdasarkan studi pendahuluan yang dilaksanakan di wilayah kerja Puskesmas Singaparna pada tanggal 2 September 2015 melalui studi dokumentasi terdapat permasalahan yaitu terdapat beberapa bidan yang tidak melakukan pendokumentasian pada kegiatan pelayanan ANC baik dari hasil anamesis, pemeriksaan fisik dan penatalaksanaan yang dilakukan. Tujuan dari penelitian ini adalah mengetahui penerapan pendokumentasian asuhan kebidanan pada antenatal care (ANC) oleh bidan di Wilayah Kerja Puskesmas Singaparna tahun 2015.

Jenis penelitian ini adalah kuantitatif dengan metode deskriptif observasional. Populasi dan sampel penelitian ini adalah Bidan yang mempunyai BPS di Wilayah Kerja Puskesmas Singaparna yang berjumlah 20 BPS Tahun 2015. Teknik pengambilan sampel dalam penelitian ini adalah dengan menggunakan teknik total sampling, artinya seluruh BPS yang ada di Wilayah Kerja Puskesmas Singaparna Tahun 2015 dijadikan sebagai sampel. Instrumen yang digunakan dalam penelitian ini adalah format cheklist yang berisi tentang daftar kegiatan pendokumentasian dari tiap pelayanan kebidanan pada ibu hamil. Format cheklist tersebut mengacu pada standar pendokumentasian atau catatan meliputi hasil anamesis, hasil pemeriksaan fisik secara head to toe, pemeriksaan penunjang, hasil diagnosa kebidanan serta penatalaksanaan asuhan kebidanan. Analisis data yang digunakan adalalah analisis univariat.

Berdasarkan hasil penelitian tentang gambaran penerapan pendokumentasian asuhan kebidanan di 20 BPS wilayah kerja Kecamatan Singaparna didapatkan kesimpulan yaitu karakteristik bidan berdasarkan umur menunjukkan bahwa usia paling muda 27 tahun dan paling tua 65 tahun, rata-rata usia responden adalah 39 tahun. Pendidikan responden lulus dari D3 Kebidanan yaitu sebanyak 16 orang (80\%) lulus D4 kebidanan sebanyak 4 orang (20\%). Lama kerja responden paling baru adalah 5 tahun dan paling lama 46 tahun, rata-rata lama kerja bidan adalah 14,8 tahun. Pendokumentsian asuhan kebidanan pada ibu hamil yang dilakukan oleh bidan di BPS wilayah kerja Puskesmas Singaparna termasuk kategori kompeten sebanyak 9 orang $(45, \%)$ dan tidak kompeten sebanyak 11 orang $(55 \%)$.

Saran dalam penelitian ini agar dapat mensosialisasikan lagi tentang dokumentasi kebidanan sesuai dengan standar pendokumentasian kepada bidan yang memiliki BPS serta bagi bidan agar dapat menerapkan dokumentasi kebidanan sesuai dengan standar pendokumentasian pada setiap pelayanan kebidanan.

Kata Kunci: umur, pendidikan, lama bekerja, pendokumentasian, asuhan kebidanan 


\section{B. Latar Belakang}

Masalah kesehatan dan kematian ibu merupakan indikatror dari kesejahteraan masyarakat dan indikator pelayanan kesehatan. Berbagai upaya yang dilakukan untuk menurunkan angka kematian ibu, karena angka kematian ibu (AKI) tersebut diIndonesia masih tinggi yaitu $228 \mathrm{ibu}$ meninggal per100.000 kelahiran.Angka ini lebih 20-30 kali lipat dibanding dengan AKI di Negara tetangga.Singapura mencatat paling rendah angka ibu melahirkan, hanya 3 ibu meninggalper 100.000 kelahiran.Kemudian disusul Malaysia (5 ibu meninggal per100.000kelahiran), Thailand (8-10 per 100.000), Vietnam (50 per100.000).Indonesiatertinggi di kawasan Asia Tenggara untuk jumlah AKI (UNICEF, 2012).

Hasil RISKESDAS 2013, di Indonesia angka kematian ibu dari 318 per1000 kelahiran hidup pada tahun 1997 menurun menjadi 228 per 1000 kelahiranhidup pada tahun 2007 untuk itu berdasarkan kesepakatan global MilleniumDevelopment Goals (MDGs, 2000), pada tahun 2015 diharapkan angka kematianibu menurun sebesar tiga perempat kali dalam kurun waktu 1990 2015, dari 228menjadi 102 per 1000 kelahiran hidup pada tahun 2015. Namun kenyataannyaangka kematian ibu sampai tahun 2012 belum menurun justru meningkatmencapai 359 per 100.000 kelahiran hidup.

Kematian ibu biasanya terjadi karena tidak mempunyai akses kepelayanan kesehatan ibu yang berkualitas, terutama pelayanan kegawat daruratan tepat waktu yang dilatarbelakangi oleh terlambat mengenal tanda bahaya dan mengambil keputusan, terlambat mencapai fasilitas kesehatan, serta terlambat mendapatkan pelayanan di fasilitas kesehatan. Untuk itu pada setiap pelayananatau asuhan, harus selalu memperhatikan pencatatan atau dokumentasi. Pendokumentasian merupakan landasan hukum bagi bidan dalam pelayanan,dokumentasi dapat mengidentifikasi mutu pelayanan bidan dan dokumentasi merupakan aset berharga bidan karena data yang telah didokumentasikan dapatdipakai sebagai bahan acuan atau referensi bila terdapat suatu masalah padapelayanan asuhan yang diberikan. Bentuk dokumentasi dapat berupa SOP (Standar Operasional Prosedur) atau menggunakan Manajemen AsuhanKebidanan dengan yang lain (Sondakh, 2013 ).

Kewajiban mendokumentasikan asuhan kebidanan diatur didalam standar profesi bidan yaitu pada standar IX tentang dokumentasi yang menjelaskan bahwa asuhan kebidanan didokumentasikan sesuai dengan standar dokumentasi kebidanan yang diberikan yaitu, dilaksanakan pada setiap tahapan asuhan kebidanan, dilaksanakan secara sistematis, tepat, dan jelas serta dokumentasi merupakan bukti legal dari pelaksanaan asuhan kebidanan. Setelah memberikan asuhan kebidanan dalam layanan kebidanan bidan harus mengerjakan pendokumentasian.

Dokumentasi merupakan pertanggung-jawaban bidan terhadap apa yang telah dilakukan dalam memberikan pelayanan kebidanan. Asuhan Kebidanan merupakan salah satu penerapan fungsi dan kegiatan yang menjadi tanggung jawab dalam memberikan pelayanan kepada klien yang mempunyai kebutuhan atau masalah dalam bidang kesehatan ibu masa hamil, masa persalinan, nifas, bayi baru lahir, balita, keluarga berencana serta kesehatan reproduksi.

Alur berpikir bidan saat merawat klien meliputi tujuh langkah pendokumentsian agar mengetahui apa yang telah dilakukan bidan melalui proses berpikir sistematis dokumentasi dibuat dalam bentuk SOAP. Prinsip dari metode SOAP ini merupakan proses pemikiran penatalaksanaan manajemen kebidanan. Dokumentasi dalam kebidanan sebagai suatu bukti 
pencatatan dan pelaporan yang dimiliki oleh bidan dalam melakukan catatan perawatan yang berguna untuk kepentingan klien, bidan dan timkesehatan dalam memberikan pelayanan kesehatan dengan dasar komunikasi yangakurat dan lengkap secara tertulis dengantanggung jawab bidan. Dokumentasidalam suatu asuhan kebidanan merupakan suatu pencatatan yang lengkap dan akurat terhadap keadaan atau kejadian yang dilihat dalam pelaksanaan asuhan kebidanan.

Bidan Praktik Swasta merupakan salah satu profesi kesehatan yang selalu bersinggungan dengan masyarakat khususnya kaum perempuan atau ibu. Hal tersebutlah yang menjadikan bidan sebagai profesi yang strategis. Dengan kestrategisannya, maka diperlukan bidan berkualitas yang memiliki fondasi dan komitmen kukuh, selalu menjunjung tinggi etika, moral, serta nilai-nilai yangberlaku.

Dalam Pasal 18 ayat (1) butir (h) Peraturan Menteri Kesehatan Nomor 1464Tahun 2010 disebutkan bahwa dalam menjalankan praktik atau kerja, bidan berkewajiban untuk melakukan pencatatan asuhan kebidanan dan pelayanan lainnya secara sistematis. Pencatatan atau dokumentasi kebidanan merupakan bagian yang tidak terpisahkan dari asuhan kebidanan.

Dokumentasi kebidanan menjadi sangat penting bagi seorang bidan

\section{Metode}

\section{Jenis Penelitian}

Jenis penelitian ini adalah observasional. Penelitian ini merupakan penelitian deskriptif yang bertujuan untuk memaparkan (mendeskripsikan) peristiwa-peristiwa yang terjadi saat ini. Deskripsi peristiwa dilakukan secara sistematis dan lebih menekankan data faktual dari pada penyimpulan. Penelitian deskriptif ini hanya mengungkap atau mengekplorasi kejadian yang merupakan fakta-fakta karena merupakan bentuk tanggung jawab dalam pelayanan kebidanan, dokumentasi kebidanan tersebut terdiri dari dokumentasi asuhan kebidanan meliputi formulir informed consent, formulir ANC, formulir partograf, formulir persalinan atau nifas dan KB, formulir laporan, formulir surat kelahiran, formulir surat kematian, formulir surat keterangan cuti bersalin, formulir permintaan darah, dan buku KIA (Yulifah, 2009).

Berdasarkan studi pendahuluan yang dilaksanakan di wilayah kerja Puskesmas Singaparna pada tanggal 2 September 2015 melalui studi dokumentasi terdapat permasalahan yaitu terdapat beberapa bidan yang tidak melakukan pendokumentasian pada kegiatan pelayanan ANC baik dari hasil anamesis, pemeriksaan fisik dan penatalaksanaan yang dilakukan.

Berdasarkan uraian tersebut, penulis bermaksud melakukan penelitian mengenai penerapan bidan dalam pengisian pendokumentasian baik asuhan pada ibu hamil di wilayah kerja Puskesmas Singaparna tahun 2015.

Tujuan dari penelitian ini adalah mengetahui penerapan pendokumentasian asuhan kebidanan pada antenatal care (ANC) oleh bidan di Wilayah Kerja Puskesmas Singaparna tahun 2015.

dan memaparkan apa adanya tentang keadaan dokumentasi asuhan kebidanan di Wilayah Kerja Puskesmas Singaparna Tahun 2015.

\section{Populasi dan Sampel}

Bidan yang mempunyai BPS di Wilayah Kerja Puskesmas Singaparna yang berjumlah 20 BPS Tahun 2015. Teknik pengambilan sampel dalam penelitian ini adalah dengan menggunakan teknik total sampling, artinya seluruh BPS yang ada di 
Wilayah Kerja Puskesmas Singaparna Tahun 2015 dijadikan sebagai sampel.

\section{Waktu dan Tempat Penelitian}

Lokasi penelitian yaitu di Wilayah Kerja Puskesmas Singaparna yang. Sasaran penelitian yaitu klinik bersalin atau bidan praktik mandiri yang ada di Wilayah Kerja Puskesmas Singaparna Tahun 2015.

\section{Variabel penelitian}

Variabel dalam penelitian ini adalah penerapan pendokumentasian asuhan kebidanan di BPS pada ibu hamil.

\section{Instrumen penelitian}

Instrumen yang digunakan dalam penelitian ini adalah format cheklist yang berisi tentang daftar kegiatan pendokumentasian dari tiap pelayanan kebidanan pada ibu hamil. Format cheklist tersebut mengacu pada standar pendokumentasian atau catatan meliputi hasil anamesis, hasil pemeriksaan fisik secara head to toe, pemeriksaan penunjang, hasil diagnosa kebidanan serta penatalaksanaan asuhan kebidanan.

\section{Analisis Data}

Analisis data yang digunakan adalalah analisis univariat untuk menganalisis penerapan pendokumentasian pada asuhan kebidanan menggunakan rumus :

$$
P=\left(\frac{F}{N}\right) x 100 \%
$$

$$
\begin{aligned}
\text { Ket : } & \mathrm{P}=\text { Presentase } \\
& \mathrm{F}=\text { Jumlah item yang diisi } \\
& \mathrm{N}=\text { Jumlah standar item } \\
& \text { pendokumentasian }
\end{aligned}
$$

\section{Hasil penelitian}

\section{Tenaga Kerja di Puskesmas Singaparna}

Tabel 5.1

Tenaga kerja di Puskesmas Singparna

\begin{tabular}{|l|l|c|c|}
\hline No & \multicolumn{1}{|c|}{ Jenis } & Standar & Jumlah \\
\hline 1. & Kepala Puskesmas & 1 & 1 \\
\hline 2. & dokter umum & 2 & 3 \\
\hline 3. & dokter gigi & 1 & 1 \\
\hline 4. & Perawat Gigi & 1 & 3 \\
\hline 5. & Bidan PKM & 2 & 4 \\
\hline 6. & Bidan Desa & 16 & 16 \\
\hline 7. & Perawat & 5 & 10 \\
\hline 8. & Tenaga kefarmasian & 1 & 1 \\
\hline 9. & Tenaga kesmas & 1 & 2 \\
\hline 10. & Tenaga gizi & 2 & 1 \\
\hline 11. & Tenaga sanitasi & 1 & 1 \\
\hline 12. & Juru Imunisasi & 1 & 1 \\
\hline 13. & TU & & \\
\hline
\end{tabular}

Data pada tabel diatas menunjukkan bahwa jumlah tenaga kesehatan yang belum memenuhi standar minimal adalah tenaga sanitasi yaitu sebanyak 1 orang sedangkan jumlah standar sebanyak 2 orang.

\section{Karakteristik responden}

Berdasarkan hasil penelitian diperoleh beberapa karakteristik responden seperti umur, pendidikan, lama kerja dan pelatihan. Berikut ini peneliti sajikan gamabran karakteritik responden. 
a. Umur

Tabel 5.1

Usia reponden di wilayah kerja Puskesmas Singaparna

\begin{tabular}{|l|c|c|c|c|c|}
\hline & N & Min & Maks & Rata-rata & SD \\
\hline Umur & 20 & 27 & 65 & 39.15 & 10.358 \\
\hline $\begin{array}{l}\text { Valid N } \\
\text { (listwise) }\end{array}$ & 20 & & & & \\
\hline
\end{tabular}

Beradasarkan data pada tabel 5.2 menunjukkan bahwa usia paling muda 27 tahun dan paling tua 65 tahun, rata-rata usia responden adalah 39 tahun.

b. Pendidikan

Tabel 5.3

Distribusi frekuensi pendidikan responden

\begin{tabular}{|l|c|c|}
\hline \multicolumn{1}{|c|}{ Pendidikan } & Frekuensi & Persentasi (\%) \\
\hline D3 Kebidanan & 16 & 80.0 \\
\hline D IV Kebidaan & 4 & 20.0 \\
\hline Total & 20 & 100.0 \\
\hline
\end{tabular}

Data pada tabel 5.3 menunjukkakn bahwa mayoritas pendidikan responden lulus dari D3 Kebidanan yaitu sebanyak 16 orang (80\%) lulus D4 kebidanan sebanyak 4 orang $(20 \%)$.

c. Lama kerja

Tabel 5.4

Lama kerja responden

\begin{tabular}{|l|c|c|c|c|c|}
\hline & N & Min & Maks & Rata-rata & SD \\
\hline Lama_Krj & 20 & 5 & 46 & 14.85 & 11.536 \\
\hline Valid N (listwise) & 20 & & & & \\
\hline
\end{tabular}

Lama kerja responden paling baru adalah 5 tahun dan paling lama 46 tahun, ratarata lama kerja bidan adalah 14,8 tahun.

d. Pelatihan

Tabel 5.5

Distribusi frekuensi pendidikan responden

\begin{tabular}{|l|c|c|}
\hline Pelatihan & Jumlah & Persentase \\
\hline APN & 20 & 100 \\
\hline ABPK & 20 & 100 \\
\hline CTU & 20 & 100 \\
\hline
\end{tabular}

Dari 20 orang responden yang diteliti, seluruh responden telah mengikuti pelatihan APN, CTU.ABPK.

\section{Penerapan Pendokumentasian Asuhan Kebidananpada ibu hamil}

Tabel 5.6

Penerapan Pendokumentasian Asuhan Kebidanan pada ibu hamil di BPS wilayah kerja puskesmas Singaparna 


\begin{tabular}{|c|c|c|}
\hline Pendokumentasian & Jumlah & Persentase \\
\hline Kompeten & 9 & 45.0 \\
\hline Tidak kompeten & 11 & 55.0 \\
\hline Total & $\mathbf{2 0}$ & $\mathbf{1 0 0 . 0}$ \\
\hline
\end{tabular}

Data pada tabel 5.6 menunjukkan bahwa pendokumentsian asuhan kebidanan pada ibu hamil yang dilakukan oleh bidan di BPS wilayah

\section{E. Pembahasan}

Hasil penelitian di 20 BPS di wilayah Singaparna Selatan dilihat dari aspek umur dalam variasi umur dalam kepemilikan BPS, namun umumnya umur bidan yang memiliki BPS rata-rata 39 tahun, halini diduga setelah menyelesaikan pendidikan formal, bidan terlebih dahulu mencari pengalaman dan belajar cara mengelola BPS dengan baik. Melihat dari aspek lamanya masa kerja bidan yang memiliki BPS yang paling banyak yaitu dengan lama kerja rata-rata 14 tahun, lama kerja ini diduga memberikan kontribusi karena bidan mempunyai pengalaman yang cukup banyak tentang pentingnya dokumentasi asuhan kebidanan. Berdasarkan tingkat pendidikan terakhir responden responden rata-rata D3 Kebidanan dan D4 Kebidanan, hal ini sudah memenuhi kualifikasi pendidikan, sesuai dengan peraturan yang diatur dalam Permenkes No. 1464/Menkes/Per/X/2010.

Data hasil penelitian dengan menggunakan alat ukur kuesioner mengenai pengetahuan responden terkait dengan pendokumentasian asuhan kebidanan sebagian besar tidak kompeten, hal ini menggambarkan responden kurang memiliki responden atau sikap tentang segala aspek yang terkait dengan dokumentasi kebidanan. Dengan pengetahuan dan kemampuan seyogyanya bidan dapat menerapkan pendokumentasian asuhan kebidanan dengan baik, karena bidan telah memiliki kompetensi pendidikan yang memadai sehingga akan fungsi dari kerja Puskesmas Singaparna termasuk kategori kompeten sebanyak 9 orang $(45, \%)$ dan tidak kompeten sebanyak 11 orang $(55 \%)$.

dokumentasi itu sendiri diantaranya dokumen kebidanan dapat dijadikan alat komunikasi dan juga dapat dijadikan barang bukti di pengadilan bila terjadi pengaduan hukum oleh klien.

Melihat dari umur responden, adaresponden yang berusia 65 tahun dalam pendokumentasian tidak lengkap, hal sesuai dengan teori yang menyatakan,jika semakin dewasa usia maka pengalaman semakin banyak, jika pengalaman semakin banyak maka pengetahuan semakin baik pula. Hal ini bisa disebabkan bidan senior yang telah berpengalaman kurang mempunyai minat untuk terus mengembangkan diri, meningkatkan pengetahuan dan mengetahui perkembangan ilmu yang ada saat ini sehingga cenderung masih lazim menggunakan praktik yang tidak didukung lagi secara ilmiah.

Dilihat dari lamanya masa kerja, adaresponden yang lama masa kerja rata-rata 14 tahun tahun, namun dalam pendokumentasian kebidanan tidak kompeten, hal ini bertolak belakang dengan teori yang menyatakan jika pengalaman seseorang semakin banyak maka semakin banyak pula pengetahuannya. Karena pengalaman adalah guru yang paling baikdan mengajarkan kita tentang apa yang telah kita lakukan, baik itu pengalamanyang baik maupun pengalaman yang buruk, sehingga kita dapat memetik hasil dari pengalaman tersebut.

Seyogyanya dengan pengalaman kerjayang banyak bidan makin mengetahui tentang aspek yang terkait 
dengan dokumentasi kebidanan, hal ini bias disebabkan bidan senior masih kurang berminat untuk menambah pengetahuannya dengan cara mengikuti seminar dan mengikuti pelatihan pelatihan.

Memperhatikan dari pendidikan terakhir responden, ada responden yang tingkat berpendidikan D4 Kebidanan yang tidak kompeten dalam pendokumentasian kebidanan. Hal ini sesuai dengan teori yang mengemukakan semakin tinggi tingkat pendidikan hidup manusia maka akan semakin berkualitas, dimana semakin tinggi pendidikan seseorang maka semakin mudah untuk menerima hal-hal yang baru dan mudah untuk menyesuaikan diri dengan hal yang baru tersebut, tapi tidak menutup kemungkinan jika pendidikannya rendah mempunyai pengetahuan yang baik.

Berdasarkan hasil observasi langsung yang dilakukan peneliti selama penelitian tentang aplikasi bidan dalam dokumentasi kebidanan yang mencakup observasi teknik pendokumentasian, sarana pencatatan dokumentasi, pengarsipan, waktu pendokumentasian, kelengkapan tanggal dan jam pendokumentasian serta tanda tangan, penggunaan tinta dan tipe-ex,serta kelengkapan dan kejelasan data dokumentasi lainnya. Berdasarkan hasil penelitian di 20 BPSdi wilayah Kecamatan Singaparna Tahun 2015, dengan menggunakan kuesioner bidan tidak mencatata pendokumentasian secara lengkap baik secara Varney, SOAP, naratif dan flowsheet dalam melakukan pendokumentasian ANC.

Akan tetapi dari kenyataan di lapanganyang dilakukan pengecekan ulang oleh peneliti dengan menggunakan metodeobservasi langsung di 20 BPS yang dibantu oleh tim dengan melihat arsip-arsip klien yang ada, dalam aspek pendokumentasian dalam bidan melakukan pendokumentasian, namun tidak kompeten karena tidak mengisi data anamnesa, pemeriksaan fisik, data penunjang, analisa, dan penatalaksanaan dengan benar dan lengkap.

Bidan

tidak menerapkanpendokumentasian dengan teknik yang benar atau bervariasi yaitu, dengan teknik naratif, tidak secara teknik flowsheet dan atau tidak memadukan pada teknik naratif dan flowsheet dalam pendokumentasian ANC. Hal ini didukung oleh penelitian sebelumnya yaitu bahwa kegiatan pendokumentasian asuhan kebidanan saat ini masih banyak menemui kesulitan, kendala ini disebabkan oleh banyaknya variasi format dokumentasi, sehingga mengalami kesulitan dalam proses pendokumentasian.

Melihat hal di atas dokumentasi dalam pelayanan kebidanan dalam pelayanan ANC belum diterapkan oleh bidan, untuk kelengkapan pendokumentasian masih ada yang kurang lengkap. Didapatkan data untuk pencatatan dokumentasi 20 BPS mencatat di buku, 1 BPS mencatat dikertas, 1 BPS mencatat dikertas dan buku, hal ini terkait semakin baik sarana penulisan dokumen maka data ini akan semakin aman. Sebanyak 11 BPS memisahkan pencatatan dokumentasi ANC menggabungkan pencatatannya dalam 1 buah buku. Hal tersebut di atas bias disebabkan bahwa pendokumentasian digabung dalam satu buku maupun dipisah tidak ada bedanya.

Data untuk waktu pendokumentasian hanya 2 BPS yang melakukan pendokumentasian pada saat pasienpulang, hal ini terkait jika pada saat pasien datang bidan melakukan pendokumentasian maka jika masih ada data yang belum lengkap masih bias ditanyakan dan dilengkapi oleh bidan.

Data penelitian untuk kelengkapan jam kunjungan, dari BPS yang melakukan pendokumentasian asuhan kebidanan tidak ada ditemukan peneliti BPS yang menuliskan jam kunjungan klien pada lembar dokumentasi, bidan 
hanya menuliskan tanggal kunjungan klien.

Dari hasil observasi ditemukan 9 BPS yang setelah selesai melakukan pendokumentasian asuhan kebidanan menyertakan tandatangan, pada hal tandatangan sebagai bukti siapa yang telah melakukan pemeriksaan pada klien, serta tidak ada BPS yang dalam kesalahan penulisan pda saat pendokumentasian tidak menggunakan tip-ex, bidan tetap menggunakan tipe-ex ketika salah dalam hal penulisan identitas dan hasil pemeriksaan, pada hal-hal tersebut kurang tepat karena bisa dianggap sebagai pemalsuan data dan hasil temuan. Hal ini bisa disebabkan karena bidan kurang mengetahui akan efek dari penggunaan tipe-ex dalam pendokumentasian.

\section{F. Simpulan dan saran}

\section{Simpulan}

Berdasarkan hasil penelitian tentang gambaran penerapan pendokumentasian asuhan kebidanan di 20 BPS wilayah kerja Kecamatan Singaparna didapatkan kesimpulan yaitu karakteristik bidan berdasarkan umur menunjukkan bahwa usia paling muda 27 tahun dan paling tua 65 tahun, rata-rata usia responden adalah 39 tahun.

Pendidikan responden lulus dari D3 Kebidanan yaitu sebanyak 16 orang (80\%) lulus D4 kebidanan sebanyak 4 orang $(20 \%)$.

Lama kerja responden paling baru adalah 5 tahun dan paling lama 46 tahun, rata-rata lama kerja bidan adalah 14,8 tahun.

\section{G. Referensi}

Haeriyanto, dkk. Faktor-faktor yang Berhubungan dengan Motivasi Perawat.

(http://jurnal.pdii.lipi.go.id/admin/jurnal/ 21063948.pdf) diakses tanggal 8 Juni 2011.
Dari semua BPS yang dilakukan penelitian hanya 3 BPS yang mengisi semua data klien dengan lengkap, singkat dan jelas sesuai dengan peraturan yang diatur dalam Kepmenkes No.369/Menkes/SK/III/2007.

Dokumentasi merupakan salah satu aspek penting diseluruh Indonesia, namun masih terlihat belum optimal untuk memberi gambaran yang utuh dalam penerapannya. Dalam dokumentasi tergambar perkembangan kondisi kesehatan klien.

Walaupun dokumentasi asuhan kebidanan sangat diperlukan untuk kepentingan klien maupun bidan akan tetapi pada kenyataannya perlengkapan pengisian dokumen masih kurang perhatian, sehingga banyak dokumentasi asuhan kebidanan yang isinya kurang lengkap.

Pendokumentsian asuhan kebidanan pada ibu hamil yang dilakukan oleh bidan di BPS wilayah kerja Puskesmas Singaparna termasuk kategori kompeten sebanyak 9 orang $(45, \%)$ dan tidak kompeten sebanyak 11 orang (55\%).

2. Saran

a. Bagi Puskesmas

Agar dapat mensosialisasikan lagi tentang dokumentasi kebidanan sesuai dengan standar pendokumentasian kepada bidan yang memiliki BPS

b. Bagi bidan

Agar dapat menerapkan dokumentasi kebidanan sesuai dengan standar pendokumentasian pada setiap pelayanan kebidanan.

Isnani, 2010. Gambaran Kinerja Perawat dalam Pendokumentasian Asuhan Keperawatan Kasus DM pada Ruang Multazam dan Firdaus di RSU

PKU Muhammadiyah Surakarta. Surakarta: 
Muhammadiyah Surakarta (http://etd.eprints.ums.ac.id/10368/3 $/ J 210060058 . P D F)$ diakses tanggal 8 Juni 2011.

\section{KEPMENKES}

369/MENKES/SK/III/2007Mahfoed z, Ircham. 2005. Pendidikan Kesehatan Bagian dari Promosi Kesehatan. Yogyakarta: Fitramaya. Muslihatun, dkk, 2009. Dokumentasi Kebidanan. Yogyakarta: Fitramaya Notoatmodjo, Soekitdjo. 2007. Promosi Kesehatan Teori Ilmu dan Perilaku. Jakarta: Rineka Cipta

Permenkes

No.

1464/MENKES/PER/X/2010. 2010. Izin dan Penyelenggaraan Praktik Bidan: Pengurus Pusat IBI.

Sastroasmoro, dkk, 2002. Dasar-Dasar Metodologi Penelitian Klinik. Jakarta: Sagung Seto.

Simatupang, Erna Juliana. 2008. Manajemen Pelayanan Kebidanan. Jakarta: EGC

Sofyan, dkk. 2006. 50 Tahun IBI Bidan Menyongsong Masa Depan. Jakarta: PPIBI
Sudarti, dkk, 2010. Buku Ajar Dokumentasi Kebidanan. Yogyakarta: Nuha Medika.

Sugiyono, 2008. Metode Penelitian Kuantitatif, Kualitatif dan R \& D. Bandung : Alfa Beta

Wildan, Hidayat, 2008. Dokumentasi Kebidanan. Jakarta: Salemba Medika

Manuaba, Ida bagus Gde. 1998. Ilmu kebidanan, penyakit kandungandan keluarga berencana. Jakarta : EGC

Mohtar, Rustam. 1998. Synopsis obstetric jilid I. Jakarta: EGC Pusdiknakes WHO, JHPIEGO, Buku konsep asuhan kebidanan. 2001.

Safiuddin, AB. 2002. Buku Acuan nasional pelayanan kesehatan dan neonatal.Jakarta: YBP,SP.

Varney, Helen. 1999. Buku saku bidan . Jakarta: EGC.

Varney, Helen. 2003 . Buku ajar asuhan kebidanan volume I. Jakarta: EGC 